\title{
A PRÁTICA PEDAGÓGICA EM PAULO FREIRE 50 ANOS DEPOIS DA PEDAGOGIA DO OPRIMIDO - INDIGNAÇÃO, ESPERANÇA E UMA PERGUNTA: COMO EDUCAR PARA A CONSTRUÇÃO DO INÉDITO VIÁVEL?
}

\author{
Ângela Maria Andrade Marinho ${ }^{i}$ \\ André Hellvig da Silva ${ }^{\text {ii }}$
}

\begin{abstract}
Resumo: Este artigo trata dos desafios da prática pedagógica fundamentada nos pressupostos da Educação Crítica, Progressista e Libertadora, a partir das idéias defendidas por Paulo Freire, em especial na sua obra Pedagogia do Oprimido. Busca-se indicar caminhos no que se refere à prática educativa para o século XXI e, por conseguinte, apresenta alguns referenciais Freireanos, que, de forma dialética, remetem-nos a repensar, quatro décadas depois, os gargalos que dificultam, ainda hoje, fazer educação de qualidade no Brasil, em especial, aquela cujos resultados tenham repercussão positiva para a sociedade, para a coletividade, resultante de uma práxis verdadeiramente conscientizadora e emancipadora. Para tanto, parte-se de um aporte teórico bibliográfico, cuja análise objetiva chamar a atenção dos profissionais da educação para a necessidade urgente de pensar criticamente a educação do século XXI, as funções das universidades e das escolas, da formação inicial e continuada de docentes e profissionais em geral e , principalmente, o perfil de egressos que desejamos formar para atuar no contexto educacional deste terceiro milênio, a partir dos pressupostos do Paradigma Crítico Progressista. Uma abordagem em Freire que, na sua Pedagogia do Oprimido, introduz ideias ainda hoje totalmente atuais, pois continuam existindo muitos oprimidos e excluídos sociais.
\end{abstract}

Palavras chave: Educação libertadora. Prática pedagógica. Inédito viável.

\section{THE PEDAGOGICAL PRACTICE IN PAULO FREIRE 50 YEARS AFTER THE PEDAGOGY OF THE OPRIMIDO - INDIGNAÇÃO, HOPE AND A QUESTION: HOW TO EDUCATE FOR THE CONSTRUCTION OF THE VIBLE UNEDIT?}

\begin{abstract}
This article discusses the challenges of teaching practice based on the assumptions of Critical Education, Progressive and Liberation from the ideas espoused by Paulo Freire, in particular its work Pedagogy of the Oppressed. We seek to indicate ways in relation to educational practice for the twenty-first century and therefore presents some benchmarks Freirean which dialectically, leads us to rethink, four decades later, the bottlenecks that hamper today, making quality education in Brazil, in particular one whose results have positive impact to society, to the community, resulting in a truly conscientization and emancipatory praxis. The starting point of a bibliographic theoretical framework whose objective analysis draw the attention of the teachers, to the urgent need for critical thinking education of XXI century, the roles of universities and schools, initial and continuing education of teachers and professionals in general, mainly, the profile of graduates who wish to train to work in the educational context of this 3rd millennium, from the assumptions Critical Paradigm Progressive, an approach in which


Freire, in his Pedagogy of the Oppressed, introduces ideas today totally current, because there remain many oppressed and socially excluded.

Keywords: Liberating education. Pedagogical practice. Untested feasibility.

\section{Introdução}

Falar em Paulo Freire, em inédito viável, é o mesmo que falar de indignação, esperança no futuro e num questionamento: como educar para construir esse inédito viável? Segundo Paulo Freire (2000, p.8), “mudar é difícil, mas é possível e urgente”. Para o professor da atualidade cabe o desafio de mudar educacionalmente, ou seja, romper com os paradigmas clássicos que explicam os cenários que vivemos hoje: o da obsolescência do conhecimento, em cujo mundo do trabalho tem vaga, mas não tem profissional com competência técnica para o desempenho das atribuições de determinado cargo. Este artigo tem como propósito apresentar algumas idéias Freireanas a partir, de uma visão de conjunto, onde foram agregados conhecimentos educacionais construídos ao longo da trajetória profissional como professores aprendizes e reflexivos, a fim de enriquecer o texto ora apresentado.

Sem dúvida, a proposta é bastante ambiciosa e não pode esgotar-se em si mesma. Por que uma abordagem crítica em Paulo Freire cinco décadas depois da Pedagogia do Oprimido? Justifica-se: com a morte deste renomado educador brasileiro em 1997, desaparece mais uma das figuras que, no período do exílio, aliaram um pensamento inquieto e impiedoso contra a prática de uma educação bancária e alienante, postando-se em favor de uma educação como prática da liberdade e do exercício consciente da cidadania. Importante dizer que Pedagogia do Oprimido nasceu em 1968, no Chile, e as idéias advindas destas lutas ainda hoje não se concretizaram na prática, por isso, a necessidade desta reflexão.

A verdade é que ainda temos muita luta pela frente para que a sociedade seja de iguais, de incluídos, a partir da ação pedagógica de professores que evidenciem em seus fazeres, o que Paulo Freire sempre defendeu:

[...] ensinar exige pesquisa, exige criticidade, exige estética e ética, exige corporeificação das palavras pelo exemplo, exige aceitação do novo e rejeição a qualquer forma de descriminação, exige reflexão crítica sobre a prática, exige consciência do inacabamento, exige alegria e esperança, exige convicção de que a mudança é possível, exige competência profissional, exige comprometimento, exige tomada conscientes de decisões, exige reconhecer que a educação é ideológica. (FREIRE, 2011, p.30) 
Acreditamos, sinceramente, que Paulo Freire é sinônimo de intelectual comprometido com a educação verdadeiramente crítica, progressista e promotora da libertação do homem, já que não há democracia efetiva sem poder crítico. Admirado por uns e não entendido por outros, Freire defende o caráter científico da educação, é adversário do fatalismo e inimigo dos ativistas. Ativista, para Freire, é o sujeito que se dedica exclusivamente à ação sem refletir criticamente sobre o que faz. É aquele sujeito que baseado em convicções dá um golpe em favor dos opressores, sem consciência ter que é justamente através de um tipo de manipulação as escuras, que as elites dominadoras vão tentando conformar as massas populares a seus objetivos. E, quanto mais imaturas, politicamente, estejam elas mais facilmente se deixam manipular pelas elites dominadoras que não podem querer que se esgote seu poder. A manipulação aparece como necessidade desse poder, a fim de conseguir a partir da inautenticidade, o aceite de um fato como verdade.

Aqueles que acompanham este educador popular vêem nele a voz da resistência científica num momento de relativismo geral. É um crítico implacável dos privilégios garantidos e do corporativismo institucional; é autor de algumas obras extremamente importantes nestes últimos cinquenta anos, entre elas, "Educação como prática da liberdade", "Pedagogia do Oprimido", "Educação e Mudança Política" e "Educação, professora sim, tia não", entre outros de igual valor acadêmico. Tentou desmontar os mecanismos elitistas de dominação e corporativismo das principais instâncias de poder no mundo contemporâneo: educação, cultura, posição na esfera estatal e mídia.

A apropriação da cultura como símbolo de distinção é um dos temas favoritos por meio do qual pretende pulverizar os modismos, o esnobismo e o vazio das elites. Quanto mais ataca, mais é legitimado como um grande baluarte do purismo intelectual em oposição à vulgaridade da indústria cultural, da mercantilização da educação e da invasão cultural. Criador ou disseminador de conceitos como “opressor”, “oprimido", "alienação", 'liberdade', “emancipação", “conscientização', “compromisso", "participação" “inédito viável”, “educação bancária”, "humanização", “educação dialógica" "práxis”, Freire vê os homens em luta pelo prestígio e pela ascensão social (opressores x oprimidos), o que somente pode ser mudado via educação, através de uma prática pedagógica compromissada com a transformação social, pois no dizer de Freire "Se a educação sozinha não transforma a sociedade, sem ela tampouco a sociedade muda". (FREIRE, 2000, p.67).

Feitas estas considerações iniciais, registramos que, por educação, entendemos um processo permanente que envolve busca, crescimento, atualização e, sobretudo, a formação sistemática intencional, moral e intelectual. Este processo efetiva-se a partir do contato com Revista Interinstitucional Artes de Educar. Rio de Janeiro, V. 4 N. 2 - pag 392-405 (mai - ago 2018): "Dossiê 50 anos da Pedagogia do Oprimido: movimentos de opressões e emancipações contemporâneas na América Latina e África" DOI:10.12957/riae.2018.38034 
outros seres humanos. Educar significa humanizar e humanizar-se, porém, isto requer partilha, e principalmente formação para viver e ensinar, conforme Paulo Freire defendia: em comunhão, mediatizada pelo mundo. Para ele, "o homem só se faz homem em contato com outros homens". (FREIRE, 2007, pp. 95-116). Educar é um processo dialético que deve proporcionar ao homem sua emancipação, e deve ser desenvolvido em favor das minorias excluídas e estigmatizadas ao longo da história, a fim de que a força do coletivo se faça presente de modo consciente e igualitário.

Como a pedagogia é a Ciência da Educação, podemos dizer que sem educação a pedagogia é pura atividade mecânica, mera rotina. Assim, a pedagogia, ainda que intimamente relacionada com a filosofia, sociologia, psicologia e didática, não depende delas, eis que é uma ciência autônoma, por isso Freire fala da importância de compreendermos com discernimento a pedagogia do oprimido, da indignação, da esperança e da autonomia.

Esta produção bibliográfica tem por objetivo resgatar o mínimo sobre a dimensão histórica do saber pedagógico defendido por Freire, visando educar para a construção do inédito viável e levar aos profissionais da educação, uma releitura crítico-reflexiva, que permeie e dê sustentação a sua prática pedagógica diária, de modo que a sua ação docente inédita, mas viável, seja problematizadora, contextualizada, dialógica e contribua para a emancipação dos envolvidos no processo ensino e aprendizagem em pleno século XXI.

A opção pela pesquisa qualitativa com abordagem dialética visa, a partir de um contexto social e histórico, abordar as contradições, os conflitos e os interesses antagônicos de cada um desses períodos, considerando a concepção de história numa perspectiva diacrônica, onde o processo conflitivo está em construção. As análises bibliográficas, aliadas as experiências vivenciadas, é que permitiram esta releitura crítico-reflexiva.

\section{0 anos depois da Pedagogia do Oprimido: como educar para o inédito viável?}

Da antiguidade, com seu processo educacional primitivo, a enculturação, chegamos a pós-modernidade com um processo educacional multicultural e uma brutal crise de identidade. Ao longo de muitos séculos, a educação continua a evoluir e, embora o pensamento pedagógico tenha surgido depois do processo educacional, o renomado educador brasileiro, Moacir Gadotti (2005), brilhantemente, traça um paralelo considerando a evolução das ideias pedagógicas e a história da educação, ambas estreitamente relacionadas. Neste contexto, fica claro que a evolução social está relacionada à evolução do pensamento pedagógico, deixando claro que estas evoluções não acontecem ou aconteceram de forma linear ou pendular, e sim de forma dialética. 
Então, das Matrizes Platônicas e Aristotélicas, avançamos para a pós-modernidade com a predominância do capitalismo e do homem burguês, aquele homem que oprime e que domina o contexto das relações sociais. A educação atual está pautada pelo multiculturalismo, onde os indivíduos, os oprimidos, a duras penas, tentam ler o mundo, compartilhar o mundo lido, dizer sua palavra, e fazer da educação, a prática da liberdade. Entendendo-se por liberdade, ação em uma direção consciente e não ação espontaneísta.

Nesse período, as grandes contribuições político-pedagógicas são importantes referências. Se de um lado consolida-se a concepção burguesa de educação, de outro lado observam-se grandes enfrentamentos, inclusive em nível de idéias, a citar as de Paulo Freire, que dão suporte a fortes movimentos sociais em defesa de uma educação justa e igualitária para todos.

Apesar de tudo, temos uma educação superior elitista e dual: conhecimentos eruditos para a classe dominante e ensino elementar para os dominados, pois as universidades, em especial as públicas, não têm conseguido acompanhar as mudanças que os novos tempos exigem. Em vez das produções científicas voltarem-se para os interesses da coletividade, da sociedade que Freire tanto defendeu, os pesquisadores rendem-se as exigências impostas pela CAPES/CNPq e continuam com práticas fechadas, pouco transparentes, que visam atender benefícios próprios em prol da famosa produtividade. Até podemos dizer que tal Pensamento Pedagógico é um pouco escolanovista, pois não questiona a sociedade classista, os privilégios e tão pouco fornece meios para o enfrentamento adequado das agruras sociais que vivenciamos enquanto educadores, professores, cidadãos do mundo. Na verdade, temos uma educação pragmática e muito pouco aquela defendida por Freire em sua pedagogia do oprimido. De acordo com Gadotti (2007, p.32)

Paulo Freire parece ter compreendido desde muito cedo que as Universidades, com seu academicismo, com suas lutas internas pelo poder e controle do conhecimento, revelamse, com frequência, como espaços estreitos, onde o pensamento criador enfrenta sérios problemas.

No entanto, com o grito dos excluídos, e as constantes críticas ao contexto sócio-político, este tipo de educação absolutamente elitizada, neoliberal, dual e excludente, devido ao aparecimento das suas fragilidades, não está se sustentando.

O fato é que o construtivismo crítico Freireano é muito fácil de ser entendido e muito difícil de ser praticado, pois exige mudanças sociais e, sobretudo, individuais.

As universidades devem compreender que tudo começa na formação inicial, ou seja, Paulo Freire compreende o processo de formação da seguinte forma: “[...] é preciso que desde os começos do processo, vá ficando cada vez mais claro que, embora diferentes entre si, quem 
forma se forma e re-forma ao formar e quem é formado forma-se e forma ao ser formado" (Iidem, p.23).

O certo é que o Pensamento Pedagógico Crítico, representado por grandes nomes no cenário educacional mundial, como Marx, Bourdieu, Foucault, Gramsci, Vygotsky e Giroux, também chegou ao Brasil com o renomado educador Paulo Freire, levantando a questão da educação bancária com práticas pedagógicas dualistas, reprodutoras das desigualdades sociais, vendo as instituições educacionais como aparelho ideológico do Estado ao se contentar em transmitir conhecimentos, cujas práticas educativas dominadoras e autoritárias servem mais aos interesses dominantes/opressores do que aos interesses dos dominados/oprimidos, já que o professor progressista tem por tarefa docente, ensinar a pensar certo e não ensinar os alunos a memorizar mecanicamente frases e idéias prontas. Este tipo de educação não passa de domesticação. E só há criticidade quando há comprometimento, lembrando que participação não significa compromisso.

Frente a este contexto, temos dois paradigmas bem definidos. As ideias opostas são defendidas pelo positivista Auguste Comte e pelo socialista Karl Marx. Enquanto o primeiro dá sustentação até hoje ao Paradigma Dominante, o segundo sustenta, na contemporaneidade, os Paradigmas Emergentes, em especial, o Paradigma Crítico ou o Materialismo Histórico-Crítico Dialético.

Defensores do Pensamento Pedagógico Positivista, Auguste Comte e o sociólogo Emile Durkhyem argumentavam em favor de uma sociedade conservadora, consensual, funcionalista, onde a ordem predominasse. Prezavam a educação baseada no poder verticalizado, fragmentado, setorizado, ou seja, justamente a educação criticada por Paulo Freire, uma educação bancária, antidialógica, descontextualizada e, portanto, educação como prática da dominação, aquela que, em vez de politizar e conscientizar, exerce função contrária, limitando e desfocando o sujeito das problemáticas emergentes centrais. A educação por Comte defendida visa formar um homem passivo, alienado, acomodado a partir da assimilação servil do conhecimento.

Contrapondo-se com veemência a este pensamento, surge o socialista Karl Marx e seus seguidores: Engels, Manacorda, Gramsci, Makarenko, que, através do Marxismo, sustentavam a superação da alienação somente pela força do coletivo e que a luta pela emancipação só seria possível a partir da luta de classes. É a relação dialética necessária que Paulo Freire caracterizava como opressores versus oprimidos. Para Marx, o conflito leva a conscientização e só assim as massas se libertam. A práxis para ser verdadeira deve decorrer da conscientização efetiva, do discernimento claro sobre alguma situação e do exercício democrático verdadeiramente crítico, 
uma vez que, de acordo com Gramsci (2014), no contexto social todos são intelectuais, mas nem todos exercem a sua intelectualidade.

De acordo com Gadotti, faz-se absolutamente necessário dizer que "a superação da contradição oprimido-opressor não implica em que os oprimidos se tornem opressores, mas a superação da condição de opressão”. (GADOTTI, 2007, p.34).

A crítica que se converte em práxis escapa da ilusão, pois ela deixa evidenciar as contradições e com isso deixa de reproduzir o status quo, ajudando a transformá-lo. No dizer de Manacorda (1996), é importante ressaltar que nenhuma batalha pedagógica pode ser separada da batalha política e social.

Fortemente influenciado por este contexto, no Brasil, duas grandes vertentes aparecem, as quais são muito bem explicadas e defendidas por José Carlos Libâneo (1996) e Dermeval Saviani (1989). Enquanto Saviani refere-se às Teorias Não-Críticas e Críticas da Educação, Libâneo classifica-as em duas grandes tendências, Pedagogia Liberal e Pedagogia Progressista.

Então, de um lado está o Pensamento Pedagógico Liberal, acrítico e, portanto, mecânico, reprodutivo, tradicional, com uma didática instrucional baseada na decoreba e com sustentação no modelo de Educação Jesuítica. É bom lembrar que os católicos e os liberais representaram correntes históricas opostas, porém não antagônicas. No dizer de Gadotti, a educação desta época reproduzia uma sociedade dividida entre os analfabetos e os sabichões. Ensino este que valoriza a obediência cega, a servilidade e as ações induzidas, exatamente o que Paulo Freire sempre combateu.

Muito tempo depois, mesmo com o advento da Escola Nova e do Tecnicismo, poucas mudanças são observadas nas práticas educacionais brasileiras. Em termos de Legislação, as idéias administrativas de Taylor e Fayol consolidam e ratificam práticas pedagógicas despolitizadas, absolutamente fragmentadas, hierarquizadas onde se evidencia claramente a compartimentalização, a eficiência, a eficácia e o produto final.

De outro lado, está o Pensamento Pedagógico Progressista libertador, tendo como maior expoente Paulo Freire (2007). Nesta linha de pensamento crítico, outros conceituados teóricos brasileiros aparecem: Moacir Gadotti, Rubem Alves, Pedro Demo, Marilena Chauí, Paulo Guiraldelli Jr., Bárbara Freitag, Ivani Fazenda, Miguel Arroyo, Darcy Ribeiro, Selma Garrido Pimenta, entre outros.

Suas ideias referem-se à importância e à necessidade de uma educação como prática da liberdade, ou seja, educação como processo de mudança, uma educação problematizadora, contextualizada, dialógica, uma educação transformadora que conduza a conscientização por meio da participação coletiva, o que contribuiria para a efetivação da Educação Cidadã, Revista Interinstitucional Artes de Educar. Rio de Janeiro, V. 4 N. 2 - pag 392-405 (mai - ago 2018): "Dossiê 50 anos da Pedagogia do Oprimido: movimentos de opressões e emancipações contemporâneas na América Latina e África" 
autônoma, promotora da verdadeira inclusão social, o que se opõe terminantemente à inclusão de fachada, visível em muitos segmentos sociais.

Para estes autores, que têm em Freire seu referencial, educar não é um ato neutro, é um ato essencialmente político e sua evolução tem caráter dialético. Por isto, somente através dessa politicidade essencial a cada homem, é que chegaremos à emancipação desejada.

Desta forma, desponta a Pós-Modernidade, enfrentando a invasão cultural. Invasão esta fruto de uma adesão não refletida. Para Stuart Hall (2006), é preciso considerar de forma fundamentada a historicidade que envolve a humanidade, para que na Pós-Modernidade se possa compreender a crise identitária que a cerca. A mercantilização da educação e a indústria cultural devem ser entendidas sob o efeito da globalização, na ótica da evolução tecnológica, que deseja a qualquer custo vender até o que não é vendável para um sujeito que está com a sua subjetividade abalada. Ainda de acordo com este autor, essa brutal crise de identidade que assola a coletividade deve ser entendida intelectualmente a partir dos descentramentos ou deslocamentos do sujeito de sua identidade, remetendo-nos a Marx, Freud, Saussure, Foucault e, ainda, ao Movimento Feminista.

Neste cenário, aparecem as questões multiculturais, plurais e de diversidade, como essenciais no âmago social. Desejamos a inclusão a partir do respeito a todas as culturas, inclusão esta que vai muito além de apenas integrar, e sim valorizar e respeitar as minorias estigmatizadas ao longo dos anos em relação à raça, etnia, gênero, idade, não só através de políticas de ações afirmativas ou estatutos, mas, sobretudo, a partir de um forte e sólido embasamento intelectual, que permita verdadeiramente igualdade de oportunidades para todos.

Assim, não podemos nos esquecer da aldeia global (MCLUHAN, 1969), na qual o homem está inserido. Aldeia esta com sujeitos totalmente individualistas que prezam muito mais as conquistas do que as partilhas. Então, sem perceber, frutos dessa invasão cultural que provoca a inautenticidade do indíviduo têm um sujeito fraco. De acordo com Pedro Demo (1994), por ser pobre politicamente não possui referências culturais, portanto, muito fácil de ser manipulado socialmente, quer em âmbito local, quer em âmbito global.

É a era do analfabetismo funcional e social, justamente porque, nesta aldeia global, o poder da comunicação audiovisual é muito rápido e, ao mesmo tempo em que informa, pode bitolar, banalizar a cultura e servir, sob influência da ideologia neoliberal, de anestesia espiritual para muitos, entretendo-os com questões sociais menos importantes.

Desejou-se que o leitor, ao ler este artigo, estabelecesse relações de significado e o fizesse de forma viva, impregnado de paixão, para que possa compreender o que é ser professor, de acordo com os ideais Freireanos, ou seja, quem é o profissional que vai educar para o inédito 
viável? Quem vai fazer um outro mundo possível? Como educar para este mundo possível? Considerando a historicidade das práticas pedagógicas e o inédito viável, podemos dizer que este outro mundo educativo é um mito ou um desafio?

Entende-se como um desafio aos verdadeiros docentes, que compromissados com seu ofício revisitam constantemente seus quefazeres e, corajosamente contribuem para a construção de um outro mundo possível, agregando experiências e conhecimentos em favor de todos aqueles sujeitos históricos que necessitam de oportunidades de formação e crescimento intelectual. Como docentes formadores não podemos, nestes novos tempos, continuar desenvolvendo velhas práticas no contexto educativo. As instituições de ensino são espaços de relações, de redes, de movimentos. Então, pensar em educação viável para um outro mundo possível significa dizer

[...] o sonho viável exige de mim pensar diariamente a minha prática; exige de mim a descoberta, a descoberta constante dos limites da minha própria prática, que significa perceber e demarcar a existência do que eu chamo espaços livres a serem preenchidos. O sonho possível tem a ver com os limites destes espaços e esses limites são históricos. A questão do sonho possível tem a ver exatamente com a educação libertadora, não com a educação domesticadora (Freire apud GADOTTI, 2007, p. 16).

Assim, precisamos trabalhar em prol da Pedagogia da Esperança, combatendo o instrucionismo e defendendo uma nova visão de currículo, onde a cooperação e a partilha não sejam mera teoria. É importante que os professores tenham consciência que as instituições públicas respondem a interesses também públicos, e que o discernimento é imperativo para que as adesões sejam fruto de reflexões e não de banalizações ou ativismos incentivados em causa própria.

É mister que o professor seja apaixonado pelo seu ofício, que tenha sede de mudança e não de poder, um profissional com sólida formação, um aprendiz permanente que saiba organizar a aprendizagem, evidenciando tolerância e coerência no seu quefazer. Então, quem vai fazer um outro mundo possível e educar para um outro mundo possível, sou eu, é você e todos aqueles que sabem que é somente via educação que podemos "transformar as pessoas que mudam o mundo" (GADOTTI, 2007, p.34). E, acima de tudo, "é alguém comprometido que luta com esperança, pois, esperança sem luta é ingenuidade e luta sem esperança é frívola ilusão". (GADOTTI, 2007, p.25).

Esse alguém é o professor, que ao ter claro que educar é produzir saberes, é construir conhecimentos, não vai, em hipótese alguma, reproduzir informações, que, em outras palavras, significa dizer repasse subalterno de saberes e fazeres descontextualizados, que de forma assistencialista e com visão reducionista contribuem para a manutenção e conservação das 
relações sociais verticalizadas e excludentes, tão presentes quatro décadas depois da Pedagogia do Oprimido.

Enfatizamos claramente que, em pleno século XXI, o desafio dos profissionais da educação não é desenvolver a memória das pessoas e sim desenvolver a capacidade que lhes é peculiar: a capacidade de pensar, que implica ler criticamente, refletir, mudar e agir conscientemente.

Neste sentido, sem formação intelectual sólida e com a indústria cultural ditando normas comportamentais e educacionais globais, na tentativa de formar um novo homem acrítico, aquele que não é capaz de apropriar-se criticamente do conhecimento e da cultura, a sociedade fica à mercê da imposição de políticas públicas, justamente pela falta de argumentos para questioná-las quanto às formas de implantação e implementação, que requer muito mais do que mero assistencialismo advindo de ações corporativistas e paternalistas.

Falando em modernidade tardia, é importante salientar que quando falamos na temática Autonomia, é interessante lembrar Freire, quando este nos remete a refletir primeiramente sobre os saberes necessários a todo o docente sério e comprometido com a prática pedagógica contemporânea. Entre elas, a capacidade de atualização permanente, a busca pela formação continuada, a capacidade de saber trabalhar em equipe, a ética e a postura profissional e a importância da iniciação científica, a pesquisa.

Entretanto, para que isto aconteça, é preciso que o profissional contemporâneo tenha claro o significado de alteridade, da ética do cuidado, para que possamos de forma reflexiva pensar em gerir uma educação que contemple a complexidade defendida por Edgar Morin, (2015) que envolve os novos tempos, ou seja, a Práxis Educativa do Século XXI.

Enfim, nesse sentido, é urgente que os profissionais da educação, conscientes do perfil de homem necessário à pós-modernidade e do seu ofício de mestre pautem suas ações nos pressupostos do Paradigma Pedagógico Crítico Progressista Libertador, que ainda hoje em pleno terceiro milênio, é pouco praticado no interior das instituições educacionais, quer em nível de educação básica, quer em nível de educação superior.

$\mathrm{Na}$ verdade, o desafio educacional é para aqueles professores que, por dever de ofício, tratam os problemas educacionais com seriedade, pois hoje, as IES, mais do que lecionadoras, através da ação dos professores, devem ser gestoras de conhecimento.

A atual crise na educação, em pleno século XXI é razão mais que suficiente para um balanço sobre as práticas e teorias que atravessaram os tempos, já que algumas teorias que orientaram muitas práticas tendem a desaparecer. Somente revisitando o passado podemos entender o futuro educacional. Neste sentido, a educação do passado estava centrada num 
paradigma que sustentava o sonho milenarista de uma sociedade plena e consensual. Entretanto, a educação do futuro centra-se na totalidade onde os paradigmas holonômicos valorizam a complementaridade, a convergência e a complexidade.

A verdade é que em pleno século XXI, estamos diante de uma encruzilhada: de um lado os profissionais da educação não dão conta da universalização da Educação Básica de Qualidade; de outro lado, as novas matrizes teóricas não se apresentam como caminhos seguros a seguir, tendo em vista que vivemos em uma época de profundas e rápidas transformações. Então como educar para o inédito viável?

É válido lembrar que a educação contemporânea será sempre uma educação contestadora e superadora dos limites impostos, pois volta-se para a transformação social, onde temas relevantes devem ser discutidos. Neste novo cenário da educação, é preciso reconstruir o saber da escola e especialmente a formação do professor. Não existe um papel cristalizado, tanto para escola quanto para o professor. Em vez da falta de caráter, da arrogância e do cinismo de quem se julga dono da verdade e do saber, os profissionais da educação devem ser criativos, flexíveis, autênticos e humildes admitindo aprender com os alunos, com os colegas e com o mundo.

Numa época de violência e agressividade, o professor deve entender-se com os seus pares, em especial com os ideologicamente diferentes, já que a escola é o espaço de convivência, onde os conflitos devem ser trabalhados e não camuflados e proliferados de forma mentirosa, antiética e, portanto, desonesta.

Assim, podemos dizer que se torna necessária e urgente uma reflexão crítica sobre a prática pedagógica, pois, de acordo com Moacir Gadotti (2000, p.86), “o professor que não estuda sempre não é profissional sério da educação", exatamente porque em pleno terceiro milênio ainda existem professores que praticam uma pedagogia conservadora, onde muitas vezes colega e alunos são humilhados, ridicularizados e medidos por uma atitude específica ou através de um determinado conhecimento solicitado em uma prova, ao contrário do que sugere a pedagogia da práxis, onde através da qual o professor dá dignidade aos alunos, aos colegas de trabalho e aposta e investe neles de modo transdisciplinar, haja vista que a prática transdisciplinar é uma exigência do próprio ato educativo, daquele professor que assume a sua identidade, seu ofício com responsabilidade, contrapondo-se àqueles pseudo profissionais da educação, que segundo Paulo Freire reduzem-se a meros tios, que inocentemente caem nesta armadilha ideológica que amacia e adoçica a sua capacidade de luta, já que se entretém com tarefas menos fundamentais no processo educativo.

O professor deve assumir sua identidade, que é educar, e educar supõe transformar, contudo, convém lembrar que não há transformação pacífica. Ela é sempre conflituosa, pois 
sempre rompe com algo enraizado: preconceitos, hábitos, comportamentos..., por isso, uma prática transformadora embasa-se sempre na pedagogia do conflito, ou seja, a pedagogia da práxis.

É mister compreendermos ainda que as instituições de ensino do futuro oferecerão cada vez menos e menos pacotes de conhecimento, devendo, entretanto, desenvolver no educando as competências e habilidades necessárias para colocar as aprendizagens construídas no ambiente educativo formal a serviço da sociedade intensiva do conhecimento.

Outro fato relevante é que, nesta sociedade intensiva do conhecimento, conforme Pedro Demo (2000) define, é preciso o entendimento de que somos aprendizes a vida toda, mas para aprender é necessário envolvermo-nos profundamente com o que desejamos aprender; é preciso, também, sabermos trabalhar em equipe, e aceitarmos o novo, as mudanças e a ideia verdadeira de atualização constante, uma vez que não basta inovarmos em cima do que já vem sendo feito, é preciso mudar e isto é mais radical, pois tem a ver com rupturas. Eis aqui o papel do verdadeiro profissional da educação, um articulador, um organizador, um intelectual que, segundo Gramsci (2014) é aquele que pesquisa e produz, um profissional que não é ingênuo nem espontaneísta.

A simplicidade é uma virtude fruto da experiência e produto da sabedoria. Por isso, o professor e/ou educador comprometido não pode abandonar a luta pela construção da cidadania, pois ela é essencial para resgatar a dignidade e o respeito que a sociedade perdeu ao longo dos anos.

\section{Conclusões}

À guisa de conclusão, registramos um apelo: é chegada a hora de compreendermos, como profissionais, de direito, da educação, o contexto atual e, junto aos alunos, rompermos com práticas e ideias não mais adequadas a este milênio, promovendo uma educação que possibilite aos egressos da educação básica e das universidades em geral, enfrentar os problemas que aí estão, para que deixemos de ser alienados e passemos, de modo emancipado, a dizer os anseios profissionais e sociais de forma verdadeiramente democrática, não confundindo o exercício crítico da cidadania com anarquia, baderna, modismo ou ativismo infundado.

Ao finalizar, é imperioso desafiar os leitores a "dar a pensar" e, pensando, concluímos que o novo brota do velho. O desafio consiste justamente em levar as pessoas a pensarem, a agirem de forma crítica e de modo compromissado. Só assim é possível construir a educação do futuro: um fazer docente que alie teoria e prática em prol de uma sociedade mais justa, politizada e igualitária. É válido lembrar que sábios professores educam pessoas para discutirem fatos 
intelectualmente, professores comuns educam pessoas para falarem superficialmente sobre coisas, e professores medíocres educam pessoas para falarem de outras pessoas. Que tipo de perfil profissional temos na pós-modernidade? Que exemplos são evidenciados no quefazer pedagógico diário dos profissionais da educação? Leia-se por quefazer, termo usado por Paulo Freire no livro Pedagogia do Oprimido: “[...] quefazer é práxis, todo fazer do quefazer tem de ter uma teoria que necessariamente o ilumine. O quefazer é teoria e prática. É reflexão e ação”. (FREIRE, 2007, p.141).

Urge, portanto, que os profissionais da educação desenvolvam no coletivo a capacidade de pensar, de refletir, e passem a agir conscientemente, discernindo a partir de discussões aprofundadas e não baseados em convicções pessoais rasas. Assim agindo, descobriremos, ainda durante o processo educacional, os encantos deste ofício milenar que é a arte de educar, mas educar supõe transformar, tirar o outro de sua zona de conforto, temporariamente inabalada.

\section{Referências}

DEMO, Pedro. Professor do Futuro e Reconstrução do Conhecimento. Rio de Janeiro: Vozes, 2004.

. Pesquisa e Construção de Conhecimento: metodologia científica no caminho de Habermas. Rio de Janeiro: Tempo Brasileiro, 2000.

FREIRE, Paulo. Pedagogia do Oprimido. Rio de Janeiro: Paz e Terra, 2007.

. Pedagogia da Autonomia. Rio de Janeiro: Paz e Terra, 2011.

. Educação e Mudança. Rio de Janeiro: Paz e Terra, 1997.

. Política e Educação. São Paulo: Cortez, 1995.

. A Educação na Cidade. São Paulo: Cortez, 2000.

. Pedagogia da Indignação: cartas pedagógicas e outros escritos. São Paulo:

UNESP, 2000.

GADOTTI, Moacir. Histórias das Idéias Pedagógicas. São Paulo: Ática, 2005. Perspectivas Atuais da Educação. Porto Alegre: Artes Médicas, 2000. . A Escola e o Professor: Paulo Freire e a paixão de ensinar. São Paulo:

Publisher, 2007. . Educação e Poder. São Paulo: Cortez, 1991. . Escola Cidadã. São Paulo: Cortez, 1997. 
GRAMSCI, Antonio. Cadernos do Cárcere. São Paulo: Civilização Brasileira, 2014. 2 v. (Série Os intelectuais)

HALL, Stuart. A Identidade Cultural na Pós-Modernidade. Rio de Janeiro: DP\&A, 2006.

LIBANEO, José Carlos. Democratização da Escola Pública: A pedagogia Crítico-Social dos Conteúdos. São Paulo: Loyola, 1996.

McLUHAN, Marshall. Os meios de comunicação como extensão do homem. São Paulo: Cultrix, 1969.

MANACORDA. Mario. História da Educação: Da Antigüidade aos Nossos Dias. São Paulo: Cortez, 1996.

MORIN, Edgar. Introdução ao pensamento complexo. Porto Alegre: Sulina, 2015.

SAVIANI, Demerval. Escola e Democracia: Teorias da Educação, Curvatura da Vara, Onze Teses sobre Educação e Política. São Paulo: Cortez, 1989.

\footnotetext{
${ }^{\mathrm{i}}$ Instituto Federal Farroupilha
}

ii Instituto Federal Farroupilha 